Artigos

\title{
Repertórios organizacionais, diferenciação regional e profissionalização da defesa de causas ambientais no Brasil
}

\author{
Organizational repertoires, differentiation and \\ professionalization of environmental activism in Brazil
}

Wilson José Ferreira Oliveira*

\begin{abstract}
Resumo: Esse artigo examina as relações entre as condições e os processos de emergência, de expansão e de diferenciação da defesa de causas ambientais e as dinâmicas de institucionalização e de profissionalização do ativismo ambiental. Trata-se de destacar, por um lado, as dinâmicas variáveis de emergência e de construção da defesa do meio ambiente como uma causa pública e, por outro, suas relações com a grande diferenciação regional das organizações vinculadas aos processos de emergência e de difusão do ativismo ambiental no Brasil.

Palavras-chave: Repertórios organizacionais. Contexto político. Engajamento individual. Defesa de causas públicas. Profissionalização. Ambientalismo.

Abstract: This article examines the conditions and processes of emergence, expansion and differentiation of environmentalism in Brazil. It focuses on the institutionalization and professionalization of environmental activism. First the article highlights the various forms of emergence and construction of environmental protection as a public cause. Then it explores the relationship between the regional differentiation of organizations and the processes of emergency and diffusion of environmental activism.
\end{abstract}

Keywords: Organizational repertoires. Political opportunities. Individual engagement. Public causes. Environmental activism.

\footnotetext{
* Doutor em Antropologia Social pela Universidade Federal do Rio Grande do Sul (Ufrgs, Porto Alegre, RS, Brasil), professor do Departamento de Ciências Sociais (DCS), do PPG em Sociologia e do PPG em Antropologia da Universidade Federal de Sergipe em Aracaju, SE, Brasil<etnografia.politica@gmail.com>.
} 


\section{Introdução}

Esse artigo examina as relações entre as condições e os processos de emergência, de expansão e de diferenciação da defesa de causas ambientais e as dinâmicas de institucionalização e de profissionalização do ativismo ambiental. ${ }^{1}$ Trata-se de destacar, por um lado, as dinâmicas variáveis de emergência e de construção da defesa do meio ambiente como uma causa pública e, por outro, suas relações com a grande diferenciação regional das organizações vinculadas aos processos de emergência e de difusão do ativismo ambiental no Brasil.

No âmbito da produção brasileira a questão da gênese social e das dinâmicas de transformação do ativismo em defesa de causas ambientais tem recebido pouca atenção. Em primeiro lugar, porque a produção nacional tem privilegiado os estudos dos processos de degradação ambiental, dos impactos socioambientais do desenvolvimento econômico e político e das estratégias alternativas representadas pelas mobilizações ambientalistas (Loureiro e Pacheco, 1995; Oliveira, 2008b, 2013). Em segundo, porque ao invés de estabelecer princípios e traços mais gerais referentes às dinâmicas de construção de causas ambientais no conjunto dos estados e regiões e que expliquem tamanha diferenciação nacional se aceita como dado que o que aconteceu nos estados e regiões que tiveram certa preponderância política na consolidação do ativismo ambiental nacional, como é o caso, entre outros, do Rio Grande do Sul, de São Paulo e Rio de Janeiro, ou estava também acontecendo nos demais, ou então explicitava uma tendência do que deveria acontecer num futuro próximo. Por fim, a própria ênfase na institucionalização dos movimentos sociais, entendida, seja como cooptação e esvaziamento dos mesmos (Goirand, 2010) seja como "organização burocrática hierárquica" e, em consequência, como tendência de institucionalização e profissionalização dos movimentos sociais, característica da tradição Michels-Weber (Clemens e Minkof, 2009; Clemens, 2010), têm sido componentes decisivos para o abandono das investigações sobre a dimensão organizacional dos processos de construção e de defesa de causas públicas.

Contrariando tais tendências, esse artigo pretende levantar algumas pistas à investigação das condições e dinâmicas diversificadas de constituição de causas ambientais em diferentes regiões do Brasil. Tal formulação nos

\footnotetext{
${ }^{1}$ Esse artigo é uma versão modificada da comunicação apresentada no $16^{\circ}$ Congresso Brasileiro de Sociologia (10-13 set. 2013, Salvador, BA). Agradeço a Emil Sobottka (debatedor) e demais participantes do GT 16 Movimentos Sociais na Atualidade: reconfigurações das práticas e novos desafios teóricos pelos comentários e sugestões.
} 
remete ao problema das condições e dos processos sociais, políticos e culturais que tornam possível a emergência de mobilizações e de protestos ambientais (Oliveira, 2013). Nesse sentido, ele se insere numa problemática de investigação mais geral referente às condições e às dinâmicas sociais, políticas e culturais de emergência e de transformação do ativismo ambiental no Brasil e constitui um desdobramento de investigações anteriores sobre as lógicas sociais de engajamento na defesa de causas ambientais (Oliveira, 2005, 2008a, 2009, 2010), como também de pesquisas atuais sobre os repertórios organizacionais e as dinâmicas de construção do meio ambiente como uma causa pública no estado de Sergipe. Para o tratamento dessa questão as análises centradas nos repertórios e dinâmicas organizacionais vinculados à defesa de determinada causa constituiu um dos ingredientes essenciais à investigação (Clemens e Minkof, 2009; Clemens, 2010). Com base em tais orientações, levanta-se a hipótese de que o contexto de abertura política e de redemocratização constitui um marco do processo de expansão e de diferenciação regional do ativismo ambiental no Brasil.

O material utilizado como fonte de informação resultou do levantamento de informações variadas. ${ }^{2}$ Em primeiro lugar, dados anteriormente coletados sobre as condições de emergência e as transformações do ativismo ambiental no Brasil (Oliveira, 2005, 2008a). Isso possibilitou estabelecer as principais mudanças ocorridas na defesa de causas ambientais no cenário brasileiro. Em segundo lugar, trata-se de artigos de jornais, de entrevistas com lideranças e de trabalhos acadêmicos sobre as dinâmicas de construção de causas ambientais em Sergipe e sua articulação com diversas reivindicações e demandas sociais e políticas. Esse tipo de informação possibilitou vincular alguns dos principais acontecimentos que caracterizaram a defesa do meio ambiente em Sergipe com as condições e dinâmicas em curso no cenário brasileiro. Por fim, a constituição de um banco de dados com informações de 957 organizações não governamentais existentes no Brasil, com base na consulta ao Cadastro Nacional de Instituições Ambientalistas (Ecolista) elaborado pelo Instituto de Estudos Ambientais Maternatura. Os dados disponíveis em tal cadastro possibilitaram estabelecer um quadro geral do associativismo ambientalista no Brasil e, principalmente, de localizar o caso de Sergipe nesse conjunto.

\footnotetext{
${ }^{2} \mathrm{O}$ s dados que servem de base para este artigo resultaram de pesquisas diversificadas que contaram com apoio da Capes (através de bolsa de doutorado), do CNPq (através de financiamento de projeto de pesquisa) e também da Universidade Federal de Sergipe (por meio do Programa Institucional de Bolsas de Iniciação Científica - Pibic). Agradeço à bolsista de iniciação científica Mayara Silva Nascimento pela construção do banco de dados sobre as organizações ambientalistas no Brasil.
} 


\section{Poluição, redemocratização e dinâmicas de construção do meio ambiente como causa pública}

A existência de organizações e de mobilizações voltadas para a defesa de causas ambientais no Brasil não se reduz à década de 1970 e nem resulta de macro processos de difusão internacional, de universalização e de globalização de causas ambientais. Isso porque os discursos e as mobilizações ambientalistas não se desenvolvem acima dos constrangimentos políticos e institucionais particulares que influenciam a adesão e a participação dos respectivos atores sociais na defesa de tais causas.

Nesse sentido, observa-se que, desde o final do século 19, a defesa de parques nacionais e de espécies animais e vegetais passou a ser objeto de formulações governamentais e da ação desenvolvida por associações ambientalistas em diferentes regiões do Brasil. Isso já foi bem salientado para certos estados das regiões Sudeste e Sul (Loureiro e Pacheco, 1995; Urban, 2001; Alonso; Costa; Maciel, 2007; Oliveira, 2008a). No estado de Sergipe, ao que tudo indica, é também nesse cenário que se encontra um dos traços da emergência do ativismo ambiental. Ou seja, semelhantemente ao que ocorreu no âmbito nacional, entre as primeiras formulações em matéria de legislação ambiental de Sergipe, está o Código Florestal Sergipano, instituído através da Lei no 656 de 3 de novembro de 1913. É também em vinculação com isso que se encontram as primeiras manifestações de personalidades contrárias à exploração dos recursos florestais, como é o caso da posição do escritor, jornalista e político Clodomir Silva e de seu Álbum de Sergipe (Guimarães, 2008).

É somente nos anos de 1970 que a questão ambiental emerge como uma questão política no Brasil, pois é a partir daí que ela passa a ser integrada à "agenda dos problemas nacionais" e os problemas ambientais começam a "ocupar espaço crescente nos meios de comunicação e na opinião pública, mobilizando grupos em torno da defesa ambiental e formando o que se pode denominar de consciência ambiental no país" (Loureiro e Pacheco, 1995, p. 138). Até então, o ativismo ambiental estava estreitamente vinculado à problemática da conservação e da preservação de sítios, paisagens e recursos naturais, assim como de espécies animais, florestas, lagos etc.

Mesmo que certas mobilizações e principais organizações criadas no início da década de 1970 mantivessem certa continuidade com essas problemáticas, esse período é caracterizado pelo questionamento da forma de organização da sociedade, de modo que somente uma mudança global nas estruturas econômicas, sociais e culturais da civilização poderia solucionar 
a crise ambiental (Mafra, 1995), como também pela utilização de novos repertórios de ação, que incluíam ações coletivas de denúncia e de mobilização da opinião pública, organização de manifestações de rua e de campanhas de politização em torno de diversos temas (Urban, 2001; Oliveira, 2005).

Tais mobilizações eram realizadas em um contexto político nacional ainda marcado pela existência de um regime autoritário, em vigor desde a segunda metade da década de 1960, e que se caracterizou, entre outros aspectos, pela limitação formal das possibilidades de participação política. Várias organizações políticas que lutaram contra o golpe militar, como o movimento estudantil e certos grupos de esquerda, haviam sido perseguidas e proibidas de se manifestar, ao passo que muitas lideranças saíram do país e passaram a viver no exílio até meados dos anos 1980 (Landim, 2002). Já na esfera internacional, em decorrência das mobilizações desenvolvidas nos anos 1960 na Europa e nos Estados Unidos, voltadas para a promoção de um espaço internacional de expressão e de reivindicação (Ollitrault, 1999), encontra-se um cenário no qual a problemática ambiental emerge como um "discurso sem opositores", como uma dessas "causas generosas que suscitam a priori a simpatia e que nenhum ator tem o interesse em colocar em causa" (Juhem, 2001, p. 10), destacando-se como um dos marcos principais do período a realização, em 1972, da Conferência de Estocolmo.

Essa combinação de um contexto político nacional fortemente fechado (Tarrow, 2009) com a emergência internacional de uma causa consensual, formada por interesses e reivindicações que dizem respeito à humanidade como um todo (Juhem, 2001; Agrikolinsky, 2002), constitui um aspecto recorrente na emergência de uma grande variedade de agências governamentais, organizações, mobilizações e formas de engajamento em defesa de causas ambientais nas diferentes regiões brasileiras.

Nesse contexto, o combate à poluição constitui um dos traços recorrentes das principais reivindicações, mobilizações e organizações que surgiram nas diferentes regiões brasileiras, podendo-se distinguir dois padrões principais: de um lado, a emergência de organizações especificamente voltadas para a defesa ambiental; de outro, a mobilização de estruturas associativas e comunitárias para obter acesso à agenda política de reivindicações econômicas, políticas e sociais diversificadas. Em certo sentido, as formas de configuração do ativismo ambiental nas diferentes regiões brasileiras resultam de combinações variadas desses dois extremos da luta em defesa de causas ambientais (Andreoli, 1992; Loureiro e Pacheco, 1995; Urban, 2001; Bones e Hasse, 2002; Alonso; Costa; Maciel, 2007; Oliveira, 2005, 2008a). 
No tocante à emergência do ativismo ambiental, observa-se que nesse contexto político nacional fortemente fechado, o discurso contra a poluição não se apresentava como uma contestação política ao "regime autoritário" vigente no Brasil, aspecto esse que, certamente, contribuiu para o sucesso inicial das mobilizações levadas adiante pelos "fundadores" das primeiras organizações ambientalistas (Oliveira, 2005; Urban, 2001). Como bem salienta um dos ativistas do período em depoimento a Dreyer (2004, p. 192): "Não éramos vistos como uma ameaça direta, como subversivos. Nosso discurso era político, mas era um conteúdo difícil de decifrar. Não estávamos falando contra o regime, falávamos contra todo um modelo".

Trata-se de um discurso cujos "constrangimentos gramaticais particulares", como salienta Juhem (2001, p. 26) a propósito do discurso humanitário, estão estreitamente vinculados às propriedades dos atores que o enunciam. Quanto a isso, cabe observar que as lideranças das principais associações e mobilizações reuniam algumas propriedades que resultavam de sua inserção simultânea no espaço internacional e nos espaços nacional e local (Pádua, 1992; Urban, 2001; Oliveira, 2005, 2008a). Nesse contexto, a origem social elevada e os vínculos com as elites dirigentes do "regime autoritário" aparece, primeiramente, como uma das características principais do recrutamento e da seleção aos postos dirigentes e constitui uma das condições que possibilitava a redução dos custos que a participação em mobilizações políticas poderia acarretar para os indivíduos nesse contexto (Oliveira, 2008a).

Nos anos de 1980, ocorreu uma grande diversificação das formas de participação na defesa de causas ambientais (Oliveira, 2005; Alonso; Costa; Maciel, 2007). Houve um aumento expressivo do número de organizações e de participantes nas mobilizações, bem como uma maior diversificação dos tipos de reivindicação e de bandeiras de luta (Carvalho e Scotto, 1995). Assim, pode-se falar da década de 1980 como o marco da "explosão" do número de associações ambientalistas brasileiras. Na origem dessas mudanças se encontram, inicialmente, certas transformações vinculadas ao chamado processo de redemocratização e que se caracterizou por uma grande afluência de organizações, grupos e lideranças dos mais diversos setores sociais que se mobilizam contra a ditadura por meio de manifestações de rua pela "democratização" (Linz e Stepan, 1999). Esse contexto foi marcado também por transformações no espaço de formação escolar e profissional decorrentes da expansão e da diversificação das redes sociais vinculadas à formação universitária e do maior entrelaçamento de organizações diversificadas que intensificou o "fenômeno da militância múltipla" (Mische, 1997; Coradini, 2002). 
Em consonância com isso, observa-se que, a partir dos anos 1980, o momento de ingresso no ativismo ambiental coincide com o início da formação universitária e com o processo de entrada no mercado de trabalho. Associado a isso, a inserção anterior ou simultânea em diversas redes de organização e de "movimento social" constituía um dos condicionantes principais do ingresso, da permanência e da ocupação de postos nas organizações e instâncias que atuavam na defesa de causas ambientais (Oliveira, 2008a). Tais aspectos estão na origem de um padrão geral de participação na defesa de causas ambientais distinto daquele encontrado no período anterior. Trata-se agora de indivíduos com origens sociais mais baixas e heterogêneas, que têm como principal base de recursos as inserções e os vínculos estabelecidos no decorrer de seus itinerários familiar, escolar e profissional com organizações e movimentos sociais diversificados (estudantis, sindicais, partidários, religiosos). Exemplos particularmente relevantes disso são as modalidades de carreiras que resultam da articulação do engajamento associativo em organizações ambientalistas com o intenso engajamento em organizações estudantis e partidárias.

Em combinação com esse padrão de emergência do ativismo, observase que a mobilização de estruturas associativas, comunitárias, religiosas e de organizações políticas e sociais diversificadas para lutar pela melhoria nas condições de vida, infraestrutura, urbanização, saúde pública etc., com base na temática ambiental, constitui igualmente um padrão característico das dinâmicas de construção de causas ambientais desde os anos de 1970 e que, ainda hoje, caracterizam a luta em defesa do meio ambiente. Em várias regiões do país, a luta contra a poluição constituiu uma forma de acesso à agenda política de questões econômicas, políticas e sociais (Loureiro e Pacheco, 1995; Urban, 2001; Bones e Hasse, 2002; Leite Lopes, 2004; Oliveira, 2005; Alonso; Costa; Maciel, 2007). É o caso das mobilizações contra o funcionamento da Indústria de Celulose Borregaard de Porto Alegre em 1970, dos conflitos envolvendo o funcionamento da fábrica de cimento de Contagem em Minas Gerais em 1975, assim como das principais medidas, formulações e órgãos de proteção ambiental criados pelo governo brasileiro, uma vez que estiveram inicialmente direcionadas para a problemática da poluição ambiental (Oliveira, 2005).

É também nesse contexto e como forma de luta comunitária em defesa de questões sociais que emerge uma das mobilizações emblemáticas da defesa do meio ambiente como uma causa pública em Sergipe: a mobilização contra a poluição causada pela implantação da Fábrica de Cimento Portland no bairro América em Aracaju (Oliveira, 2008; Oliveira, 2014). 
Trata-se da instalação da fábrica de cimento Portland, em fins dos anos 1960, num bairro estigmatizado pela proximidade da casa de detenção de Aracaju, com a promessa de geração de emprego para a população local. Todavia, para os que viviam no bairro, restaram apenas os baixos salários e a convivência diária com os "impactos negativos decorrentes da poluição atmosférica proveniente da fabricação do cimento" (Oliveira, 2008, p. 89). Tal situação foi objeto de uma série de denúncias e de busca de soluções por parte de lideranças da Associação dos Moradores e Amigos do Bairro América (Amaba), do pároco da igreja São Judas Tadeu, edificada na localidade no ano de 1961 e da própria população (Oliveira, 2008, p. 96). No entanto, foi a partir do momento em que tal questão foi assumida pelo pároco da igreja São Judas Tadeu que ela adquiriu maior "credibilidade e visibilidade", trazendo a público que, se a poluição causada pela fábrica era o "grande contribuinte para os males respiratórios" e até mesmo para os óbitos atestados, sua maior gravidade decorria de estar associada a um conjunto de carências econômicas, sanitárias, políticas e sociais que a população enfrentava desde longo tempo.

Essa forma de combinação de reivindicações de ordens sociais diversificadas nas mobilizações ambientalistas não constitui um traço específico da situação brasileira, podendo-se encontrar padrão semelhante em diferentes situações e contextos políticos nacionais (Rootes, 1999). Tais exemplos nos mostram os limites das análises do ativismo ambiental centradas na investigação das formas de institucionalização e de profissionalização do ativismo, uma vez que nesses tipos de abordagens as dinâmicas concretas e as gramáticas de construção da causa colocadas em prática nos processos de emergência e de desenvolvimento de tais mobilizações, não entram no escopo da investigação (Oliveira, 2014).

\section{Profissionalização, diversificação e diferenciação organizacional do ativismo ambiental}

Quando se examinam os dados disponíveis sobre o período de criação de associações ambientalistas em diferentes estados e regiões do Brasil, observase que, do total de 957 organizações ambientalistas existentes no cadastro nacional de instituições ambientalistas elaborado pelo Instituto de Estudos Ambientais Maternatura, 13,30\% foram criadas até finais da década de 1970. No entanto, quando nos reportamos à década de 1980, esse percentual fica em 36,10\%, e, na década de 1990, fica em 31,90\%. Quando agregamos os dados das décadas de 1980-1990, o percentual de fundação de organizações ambientalistas eleva-se para $67,90 \%$. Com base nisso, pode-se dizer que grande parte das organizações existentes até o ano de 2008 foi fundada justamente 
nos anos de 1980-1990, já que, posteriormente à década de 1990, esse índice sofre uma clara redução para $18,70 \%$. Uma constatação semelhante pode ser feita quando examinamos as informações disponíveis sobre o associativismo em outras bases de dados. Um bom exemplo disso é o levantamento feito pela Associação brasileira de organizações não governamentais (Abong) que comprova que $80,69 \%$ das organizações associadas à mesma foram criadas nas décadas de 1980-1990 (Abong, 2006), evidenciando que isso não se reduz ao caso do ativismo ambiental.

Não obstante as diferenças de abordagens, tanto a literatura nacional quanto a internacional (e mais precisamente, a europeia e norte-americana) têm abordado a grande proliferação de organizações ambientalistas ocorrida durante os anos de 1980-1990, em diferentes situações nacionais, como exemplo da tendência geral de institucionalização da ação associativa e de profissionalização de suas atividades (Ollitrault, 2001; Anquentin, 2002; Gallet, 2002; Rootes, 1999). Tal aspecto não parece ser uma característica exclusiva do movimento ambientalista, podendo ser igualmente observado na defesa dos direitos humanos e de causas humanitárias (Agrikolinsky, 2002; Siméant e Dauvin, 2002), na militância sindical (Matonti e Poupeau, 2004; Wagner, 2004), entre outros. Também a literatura nacional tem tomado a institucionalização e a profissionalização como um dos traços predominantes do ativismo ambiental (Viola, 1992, Loureiro e Pacheco, 1995; Alonso e Costa, 2002a, 2002b; Zhuori, Laschefsky, Pereira, 2005; Leite Lopes, 2004, Oliveira, 2014). Sem descartar a pertinência desse tipo de análise, quando se examina a distribuição do conjunto de ONGs vinculadas à defesa ambiental no Brasil, observa-se que existem variações significativas em relação à quantidade de organizações existentes, bem como aos recursos financeiros e organizacionais disponíveis para a estruturação e o funcionamento das associações.

Em primeiro lugar, os principais indicadores de profissionalização do associativismo comumente utilizados pela bibliografia não são tão corriqueiros no universo considerado. Assim, do total de 881 ONGs para as quais se dispõe de informações a respeito, $61,9 \%$ não contam com funcionários remunerados para a realização de suas atividades, enquanto que somente em $33,3 \%$ dos casos há entre um e 10 funcionários trabalhando na associação, e 4,8\% são aquelas que têm de 11 a 50 funcionários em seu quadro de pessoal. Tal aspecto condiz com o que se observa em termos do orçamento anual, pois, das 384 ONGs de que se dispõe de informação, apenas $20,8 \%$ têm orçamento anual de até R $\$ 500.000,00$ e, em $18 \%$ dos casos, o orçamento fica em torno dos $\mathrm{R} \$ 100.000,00$. Já para $61,2 \%$ dos casos, esse valor oscila entre $\mathrm{R} \$ 5.000,00 \mathrm{e}$ $\mathrm{R} \$ 50.000,00$. Ou seja, a grande maioria das ONGs dispõe de um orçamento 
anual suficiente apenas para aluguel e manutenção de uma sede, sem condições de recrutar e manter um quadro funcional permanente, dependendo quase que exclusivamente do trabalho de voluntários.

No tocante à distribuição regional do total de organizações ambientalistas existentes no Brasil, observa-se que 55,1\% estão localizadas no sudeste, $27,1 \%$ no sul, $9,7 \%$ no centro-oeste, $5,8 \%$ no nordeste e $2,3 \%$ no norte. Ou seja, enquanto que, num extremo, o total de associações se aproxima de 527 (sudeste), no outro, esse índice não passa de 22 (norte). Essa diferenciação em termos do número de organizações se desdobra também em marcadas distinções quanto aos indicadores de profissionalização. É também nas regiões sudeste e sul que se encontram as organizações que dispõem de maiores orçamentos anuais. Assim, entre as que dispõem de um orçamento de até $\mathrm{R} \$ 500.000,00$, um percentual de 59\% corresponde àquelas sediadas no sudeste, de $20,5 \%$ no Sul e de $14,1 \%$ no centro-oeste, enquanto que no nordeste esse índice fica em $5,1 \%$ e no norte em $1,3 \%$. Índices praticamente iguais por região são observados nos níveis orçamentários anuais menores, como o de R\$ $100.000,00$.

Tais diferenças estão associadas também ao tamanho do quadro de pessoal. Quanto a isso, observa-se que, entre as que dispõem de um a 10 funcionários, $56,8 \%$ estão sediadas no sudeste, $25,0 \%$ no sul e $11,6 \%$ no centro, enquanto que $4,1 \%$ são do nordeste e $2,1 \%$ do norte. Merece destaque, e deveria ser objeto de investigações mais aprofundadas, o fato de que quando quadro funcional varia entre 11 e 50 funcionários, as regiões nordeste e norte apresentarem índices mais expressivos que os anteriores: $56,4 \%$ são do sudeste, $17,9 \%$ do nordeste, $12,8 \%$ do sul, 7,7 do norte e 5,1\% do centro-oeste. Mesmo com essas pequenas variações regionais, a existência de associações que dispõem de um quadro funcional expressivo é algo circunscrito e particular a certos estados e regiões.

Quando se analisa o período de fundação das organizações ambientalistas conforme sua localização regional, a diferenciação regional constitui um traço constante. No caso da região sul, o percentual é de $71,40 \%$, no da sudeste é de $68,20 \%$ e no da centro-oeste é de $68,30 \%$. Já no caso das regiões norte e nordeste, tais percentuais são bem diferenciados, situando-se de forma predominante nos anos de 1990-2000. Assim, observa-se que, na região nordeste, um percentual de 42,90\% corresponde às organizações que foram criadas nos anos de 2000, e de 38,10\% àquelas fundadas nos anos de 1990, enquanto que na região Norte esses percentuais são, respectivamente, de $52,90 \%$ e de $29,40 \%$. Desse modo, no caso das regiões Norte e Nordeste, são raras as associações criadas durante os anos de 1990 e, quando isso ocorre, 
trata-se, geralmente, de organizações voltadas à problemática conservacionista e de proteção dos animais. Tais características estão associadas a diferenças no tocante à articulação das ONGs com redes nacionais e internacionais de movimentos sociais. Ou seja, do total de ONGs ambientalistas que fazem parte do Fórum Brasileiro de ONGs e Movimentos Sociais para o Meio Ambiente e Desenvolvimento (FBOMS), apenas 1,40\% são da região norte e $3,80 \%$ do nordeste, enquanto que no sudeste é de $63,20 \%$, de $20,30 \%$ no sul e de $11,30 \%$ na região centro-oeste.

Tais diferenças não constituem aspectos de pouca importância para a compreensão das condições e dinâmicas de emergência e de constituição das mobilizações ambientalistas no Brasil. Elas remetem a diferenças significativas quanto aos graus e tipos de estruturas e de recursos organizacionais (McCarthy e Zald, 1977; Alonso, 2009), vinculados à defesa de causas ambientais nas respectivas regiões do Brasil. E, como tais, demonstram o quanto as caracterizações do ativismo ambiental a partir de tendências de institucionalização e profissionalização não podem ser aceitas como dadas e evidentes. No entanto, tais variações nas formas de organização e de funcionamento das organizações ambientalistas, não devem ser tomadas como uma divisão entre regiões com maior organização (sul e sudeste, principalmente) e aquelas com menor organização (norte e nordeste) (Avritzer, 2007).

Contrariamente a isso, tal análise nos coloca diante de dois tipos principais de estruturas e de recursos organizacionais: de um lado, regiões em que a emergência do ativismo ambiental ocorreu no início da década de 1970 e se desdobrou na criação, durante os anos de 1980-1990, de um número significativo de organizações e da maior concorrência entre elas por recursos financeiros e organizacionais de fundações e organizações nacionais e internacionais (Loureiro e Pacheco, 1995; Oliveira, 2008a); de outro lado, regiões em que a emergência de organizações ambientalistas ocorreu num período mais recente e em que suas estruturas e recursos organizacionais estão intensamente interligados a outros tipos de associações, estruturas comunitárias, organizações civis e autoridades sociais.

Mais do que simplesmente indicar tais diferenças, o desafio principal colocado por tais dados consiste em examinar as condições sociais, políticas e culturais de possibilidade dessa forte diferenciação regional do ativismo ambiental. Por um lado, elas dizem respeito a traços centrais das estruturas organizacionais e políticas vinculadas aos processos de emergência, de consolidação ou de declínio de coletividades ou grupos mobilizados (Pierru, 2010; McAdam; McCarthy; Zald, 1996). Por outro, às relações propriamente 
políticas que podem pesar de maneira favorável ou desfavorável ao surgimento e à diferenciação de mobilizações e movimentos sociais (Alonso, 2009; Tarrow, 2009; Mathieu, 2002, 2010; Toni, 2001). Por fim, aos processos concretos de construção da defesa ambiental como um "problema público" e, principalmente, de sua associação com causas diversificadas (Cefaï, 1996, 2009).

Isso nos permite justamente evitar o perigo de reduzir a dimensão organizacional a uma mera identificação da quantidade e dos tipos de organizações e de recursos disponíveis, colocando-nos o desafio de dar conta das diferentes combinações entre as organizações envolvidas, as lideranças e grupos mobilizáveis, as características do contexto político e as dinâmicas de construção de causas públicas.

\section{Conclusões}

Esse artigo analisou as condições e formas de expansão e de diversificação regional das organizações, mobilizações e protestos em defesa de causas ambientais. O ponto de partida foi questionar algumas generalizações que têm sido feitas sobre o ativismo ambiental, tais como "profissionalização", "institucionalização" etc., com base na investigação dos processos diferenciados de emergência da defesa de causas ambientais nas diferentes regiões do Brasil.

Tal questão não tem recebido a devida atenção por parte da literatura pertinente. Dentre os fatores que têm contribuído para isso, encontra-se, primeiramente, o pressuposto de que os acontecimentos observados em determinadas realidades locais e regionais resultam de dinâmicas mais gerais que dizem respeito ao Brasil como um todo. Isso aparece com mais propriedade nas pesquisas realizadas na região Sudeste. Nesses casos, as características políticas e culturais próprias de tal região são automaticamente tomadas como propriedades do ativismo ambiental no Brasil. Em segundo lugar, tais tentativas partem de pressupostos políticos e ideológicos que dividem as regiões do país entre aquelas "mais participativas" e as "menos participativas" (Avritzer, 2007). Por fim, existem ainda aqueles trabalhos que importam os conceitos, metodologias e interpretações dominantes na Europa e nos EUA como explicações "homogêneas" para dar conta dos fenômenos associados ao engajamento político no Brasil (Goirand, 2010; Oliveira, 2013).

Tentando ir além dessas dificuldades, a investigação que levamos a cabo demonstrou que a investigação dos recursos organizacionais e de suas relações com o ambiente político onde estão inseridos os movimentos sociais constitui uma dimensão pertinente para a apreensão de certas diferenças e particularidades quanto aos princípios e graus de estruturação organizacional 
dos processos de emergência e de desenvolvimento de organizações e mobilizações coletivas. Dessa forma, foi possível identificar as estruturas organizacionais e políticas vinculadas à defesa de causas ambientais no Brasil que são muito diversificadas e que não correspondem às referidas generalizações.

Associado a isso, a análise dos ativistas e das lideranças e de suas dinâmicas de engajamento individual na defesa do meio ambiente, constituiu uma forma pertinente de apreender o quanto o processo de expansão e diversificação das organizações foi acompanhado por mudanças nas características e nas modalidades e padrões de carreiras militantes daqueles que se engajam nesse tipo de causa. Nesse sentido, uma das conclusões que tal análise conduziu diz respeito à importância da articulação entre análises sobre as estruturas políticas e organizacionais e aquelas voltadas para a apreensão das lógicas sociais do engajamento individual para uma melhor compreensão das condições de emergência e de transformação do ativismo ambiental no Brasil.

A análise da dinâmica concreta de construção da poluição como um problema público em Sergipe constituiu uma das vias para evidenciar a articulação entre estruturas organizacionais, dinâmicas políticas e lógicas do engajamento individual a partir de processos concretos de construção da defesa ambiental como um problema público e de sua associação com causas diversificadas. A presença de estruturas organizacionais e comunitárias e de atores que não estavam voltados especificamente para a proteção ambiental, mas que tiveram um papel central na emergência da causa ambiental como um problema público, constituiu um aspecto importante na configuração da defesa ambiental em tal situação. Longe de constituir um caso isolado, observa-se que, em várias regiões do país, a luta contra a poluição constituiu uma forma de acesso de causas diversificadas à agenda política. Por isso, tomar a expansão e a diferenciação do ativismo ambiental levando-se em conta apenas as organizações e atores voltados especificamente para a defesa do meio ambiente pode nos conduzir à elaboração de quadros bastante distorcidos e que não dão conta das diversas formas que as mobilizações e lutas ambientais tomaram nas diferentes regiões do país no decorrer do tempo.

Ainda que diversos estudos tenham demonstrado o quanto o contexto político denominado de abertura política e de redemocratização constitui um marco do processo de expansão e de diferenciação regional do ativismo ambiental no Brasil, isso não quer dizer que as dinâmicas de configuração das formas de mobilização em defesa de causas ambientais sejam idênticas nas diferentes regiões do país. Para isso, é necessário dedicar maior atenção às dinâmicas de configuração da defesa do meio ambiente com base na 
comparação das formas de combinação entre estruturas organizacionais e políticas, dinâmicas de engajamento individual e processos concretos de construção de causas ambientais. Dito de outro modo, tal desafio implica que se considere a emergência de organizações especificamente voltadas para a defesa ambiental e a mobilização de estruturas associativas e comunitárias para acesso de reivindicações econômicas, políticas e sociais diversificadas à agenda política, como aspectos interdependentes das dinâmicas de construção do meio ambiente como causa pública.

Dessa forma, as análises das condições de emergência e das dinâmicas de transformação do ativismo ambiental no Brasil poderiam, finalmente, operar uma espécie de "descentramento" (Balandier, 2006) em relação às comparações que postulam uma hierarquia valorativa entre as situações que têm mais e as que têm menos organização, participação, mobilização etc., com base na idealização de certas situações ocidentais como protótipo de organização, de ativismo e de mobilização em defesa de causas ambientais. Trata-se, portanto, de colocar no centro da análise a importância de compreender a mobilização em defesa de causas ambientais em sua conexão com diferentes grupos e espaços sociais, bem como em "lugares" e a partir de "categorias" e "práticas" próprias aos atores, às quais muitas vezes são negligenciadas ou tidas como "não políticas" e até mesmo como "apolíticas" (Memmi, 1985). Desse modo, a comparação se direciona para a apreensão das formas de configuração como resultado de combinações variadas entre estruturas organizacionais e políticas, modalidades de carreiras de ativistas e pluralidade de modos de constituição de coletividades em defesa de causas ambientais.

Ao que tudo indica tal desafio ainda está muito distante da produção atual, uma vez que ela persiste em priorizar a importação "homogênea" de problemáticas, conceitos e metodologias das principais vertentes dominantes (Goirand, 2009; Oliveira, 2013), em vez de priorizar o diálogo e o confronto de tais perspectivas com base na investigação concreta das semelhanças e particularidades colocadas pelas condições de emergência e dinâmicas de transformação da defesa de causas ambientais no Brasil.

\section{Referências}

ABONG. Associação brasileira de organizações não governamentais. ONGs no Brasil: perfil das associadas à Abong. São Paulo: Abong, 2006.

AGRIKOLINSKY, E. La ligue française des droits de l'homme et du citoyen depuis 1945. Paris: L'Harmattan, 2002.

ALONSO, Â. As teorias dos movimentos sociais - um balanço do debate. Lua Nova, v. 76, p. 49-86, $2009<$ dx.doi.org/10.1590/S0102-64452009000100003>. 
ALONSO, Â.; COSTA, V. Ciências Sociais e meio ambiente no Brasil: um balanço bibliográfico. $B I B$, n. 53, p. 35-78, 2002a.

ALONSO, Â.; COSTA, V. Por uma sociologia dos conflitos ambientais no Brasil. In: H. Alimonda (org.). Ecología política: naturaleza, sociedad y utopía. Buenos Aires: Clacso, 2002b, p. 115-135.

ALONSO, Â.; COSTA, V.; MACIEL, D. A. Identidade e estratégia na formação do movimento ambientalista brasileiro. Novos Estudos Ceprab, 79, p. 151-167, 2007 <dx.doi.org/10.1590/S0101-33002007000300008>.

ANDREOLI, C. V. Principais resultados da política ambiental brasileira: o setor público. Revista de Administração Pública, v. 26, n. 4, p. 10-31, 1992.

ANQUENTIN, V. Produire une politique municipale de l'environnement: La regulation des interactions des acteurs locaux par 1'“expertise” In: P. Hamman; J-M. Méon; B. Verrier. Discours savants, discours militants: mélange des genres. Paris: L'Harmattan, 2002. p. 129-151.

AVRITZER, L. (org.). A participação social no Nordeste. Belo Horizonte: EdUFMG, 2007.

BALANDIER, Georges. Voir ailleurs, pouvoir ici. Raisons Politiques, n. 22, p. 15-22, 2006.

BONES, E.; HASSE, G. Pioneiros da ecologia: breve história do movimento ambientalista no Rio Grande do Sul. Porto Alegre: Já Editores, 2002.

CARVAlHO, I. C. de M.; SCOTTO, G. (orgs.). Conflitos socioambientais no Brasil. Rio de Janeiro: Graphos, 1995. p. 25-101.

CEFAÏ, D. Comment se mobilise-t-on? L'apport d'une approche pragmatiste à la sociologie de l'action collective. Sociologie et Sociétés, v. 41, n. 2, p. 245-269, 2009 $<$ dx.doi.org/10.7202/039267ar>.

CEFAÏ, D. La construction des problèmes publics: définitions de situations dans des arènes publiques. Réseaux, v. 14, n. 75, p. 43-66, 1996 <dx.doi.org/10.3406/ reso.1996.3684>.

CLEMENS, Elisabeth S. Repertórios organizacionais e mudança institucional: grupos de mulheres e a transformação da política nos EUA, 1890-1920. Revista Brasileira de Ciência Política, n. 3, p. 161-218, 2010.

CLEMENS, Elisabeth S.; MINKOFF, Debra. Beyond the Iron law: rethinking the place of organizations in social movement reserach. In: David A. Snow; Sarah A. Soule; Hanspeter Kriese (orgs.). The Blackwell companion to social movements (Blackwell Companions to Sociology). Oxford: Blackwell Publishing, 2009. p. 155-170.

CORADINI, O. L. Escolarização, militantismo e mecanismos de participação política. In: B. Heredia et al. (org.). Como se fazem eleições no Brasil. Rio de Janeiro: RelumeDumará, 2002. p. 103-153.

DREYER, L. Sinfonia inacabada: a vida de José Lutzenberger. Porto Alegre: Vidicom Audiovisuais Edições, 2004. 
GALLET, G. L'expertise, outil de l'activisme environnemental chez Greenpeace France. In: P. Hamman; J-M. Méo; B.Verrier. Discours savants, discours militants: mélange des genres. Paris: L'Harmattan, 2002. p. 109-128.

GOIRAND, Camille. Penser les mouvements sociaux d'Amérique Latine: les approches des mobilisations depuis les anneés 1970. Revue Française de Science Politique, v. 60, n. 3, p. 445-466, $2010<$ dx.doi.org/10.3917/rfsp.603.0445>.

GUIMARÃES, R. M. A. M. Estado e politica ambiental em Sergipe. São Cristóvão, 2008. (Dissertação de mestrado em Desenvolvimento e Meio Ambiente, PPG em Desenvolvimento e Meio Ambiente, Universidade Federal de Sergipe).

JUHEM, P. La légitimation de la cause humanitaire: Un discours sans adversaires. Mots, n. 65, p. 9-27, $2001<$ dx.doi.org/10.3406/mots.2001.2484>.

LANDIM, L. Experiência militante: história das assim chamadas ONGs. Lusotopie, n. 1, p. 215-239, 2002.

LEITE LOPES, J. S. A ambientalização dos conflitos sociais: participação e controle público da poluição industrial. Rio de Janeiro: Relume-Dumará, 2004.

LINZ, J. J.; STEPAN, A. A transição e consolidação da democracia: a experiência do Sul da Europa e da América do Sul. São Paulo: Paz e Terra, 1999.

LOUREIRO, M. R.; PACHECO, R. S. Formação e consolidação do campo ambiental no Brasil: consensos e disputas (1972-1992). Revista de Administração Pública, v. 29, n. 4, p. 137-153, 1995.

MAFRA, H. (org.). Desafios e perspectivas do movimento ambientalista no Brasil. Brasília: Fundação Francisco, 1995.

MATHIEU, L. Contexte politique et opportunités. In: O. Fillieule; E. Agrikoliansky; I. Sommier. Penser les mouvements sociaux: conflits sociaux et contestations dans les societés contemporaines. Paris: La Découverte, 2010. p. 39-54.

MATHIEU, L. Rapport au politique, dimensions cognitives et perspectives pragmatiques dans l'analyse des mouvements sociaux. Revue Française de Science Politique, v. 52, n. 1, p. 75-100, 2002 <dx.doi.org/10.3406/rfsp.2002.403696>.

MATONTI, F.; POUPEAU, F. O capital militante: tentativa de definição. Tradução: Ernesto Seidl. Actes de la Recherche en Sciences Sociales, n. 155, p. 5-11, 2004.

MCADAM, D.; MCCARTHY, J. D.; ZALD, M. N. (orgs.). Comparative perspectives on social movements: political opportunities, mobilizing estructures and cultural framings. Cambridge: Cambridge University Press, 1996 <dx.doi.org/10.1017/ CBO9780511803987>.

MCCARTHY, J. D.; ZALD, M. Resource mobilization and social movements: A partial theory. The American Journal of Sociology, v. 82, n. 6, p. 1212-1241, 1977 $<$ dx.doi.org/10.1086/226464>.

MEMMI, D. L'Engagement politique. In: M. Grawitz; J. Leca. Traité de Science Politique: L'action politique, v. 3. Paris: PUF, 1985. p. 310-366.

MISCHE, A. De estudantes a cidadãos: redes de jovens e participação política. Revista Brasileira de Educação, n. 5 e 6, p. 134-150, 1997. 
OLIVEIRA, V. M. S. Movimento social e conflitos socioambientais no Bairro América - Aracaju, SE: o caso da Companhia de Cimento Portland de Sergipe (1967-2000). Aracaju, 2008 (Dissertação de mestrado em Desenvolvimento e Meio Ambiente, UFS).

OLIVEIRA, W. J. F. de. "Paixão pela natureza”, atuação profissional e participação na defesa de causas ambientais no Rio Grande do Sul entre 1970 e início dos anos 2000. Porto Alegre, 2005 (Tese de doutorado em Antropologia Social, PPG em Antropologia Social, Ufrgs) .

OLIVEIRA, W. J. F. de. Gênese e redefinições do militantismo ambientalista no Brasil. Dados - Revista de Ciências Sociais, v. 51, n. 3, p. 751-777, 2008a <dx.doi. org/10.1590/S0011-52582008000300007>.

OLIVEIRA, W. J. F. de. Maio de 68: mobilizações ambientalistas e sociologia ambiental. Mediações - Revista de Ciências Sociais. Londrina, v. 13, n.1-2, p. 87-108, 2008 b <dx.doi.org/10.5433/2176-6665.2008v13n1\%2F2p87>.

OLIVEIRA, W. J. F. de. Posição de classe, redes sociais e carreiras militantes no estudo dos movimentos sociais. Revista Brasileira de Ciência Política, v. 3, p. 49-77, 2010.

OLIVEIRA, W. J. F. de. A arte de resistir às palavras: inserção social, engajamento político e militância múltipla. In: Ernesto Seidl; Igor Gastal Grill (org.). As ciências sociais e os espaços da política no Brasil, v. 1. Rio de Janeiro: Fundação Getúlio Vargas, 2013. p. 141-178.

OLIVEIRA, W. J. F. de. Gênese e diferenciação do ambientalismo. In: W. J. F. de Oliveira (org.). Engajamento e militância politica em Sergipe: contexto político, engajamento individual e atuação profissional. São Cristóvão: Edufs, 2014. p. 27-64.

OLLITRAULT, S. De la caméra à la pétition-Web: le répertoire médiatique des écologistes. Réseaux, Paris: Hermès Science Publications, n. 98, p. 153-185, 1999 $<$ dx.doi.org/10.3406/reso.1999.2183>.

PÁDUA, J. A. O nascimento da política verde no Brasil: fatores exógenos e endógenos. Revista Ciências Sociais Hoje, São Paulo: Vértice, 1992. p. 190-216.

PIERRU, E. Organisations et ressources. In: O. Fillieule; E. Agrikolinsky; I. Sommier. Penser les mouvements sociaux: conflits sociaux et contestations dans les societés contemporaines. Paris: La Découverte, 2010. p. 19-38.

ROOTES, C. (org.). Environnmental movements: local, national and global. London: Frank Cass, 1999.

SIMÉANT, J.; DAUVIN, P. Le travail humanitaire: les acteurs des ONG, du siege au terrain. Paris: Presses de Sciences Po, 2002.

TARROW, S. O poder em movimento: movimentos sociais e confronto político. Petrópolis: Vozes, 2009.

TONI, F. Novos rumos e possibilidades para os estudos dos movimentos sociais. BIB - Revista Brasileira de Informação Bibliográfica em Ciências Sociais, n. 52, p. 79-104, 2001.

URBAN, T. Missão (quase) impossível: aventuras e desventuras do movimento ambientalista no Brasil. São Paulo: Editora Fundação Peirópolis, 2001. 
VIOLA, E. O movimento ambientalista no Brasil, 1971-1991: da denúncia e conscientização pública para a institucionalização e o desenvolvimento sustentável. Ciências Sociais Hoje, v. 12, p. 132-161, 1992.

WAGNER, A. C. Syndicalistes européens: Les conditions sociales et institutionnelles de l'internationalisation des militants syndicaux. Actes de la Recherche en Sciences Sociales, n. 155, p. 13-34, $2004<$ dx.doi.org/10.3917/arss.155.0012>.

ZHOURI, A.; LASCHEFSKY, K.; PEREIRA, D. B. A insustentável leveza da política ambiental: desenvolvimento e conflitos socioambientais. Belo Horizonte: Autêntica, 2005.

Recebido em: 13 fev. 2015

Aprovado em: 30 set. 2015

Autor correspondente:

Wilson José Ferreira Oliveira

Av. Marechal Rondon, s/n

Jardim Roza Elze

49100-000 São Cristóvão, SE, Brasil 